\title{
Indications and Outcome of Gynaecological Hysterectomy at Aminu Kano Teaching Hospital, Kano: A 5-Year Review
}

\author{
Zainab Datti Ahmed*, Nafi'ah Taiwo \\ Department of Obstetrics and Gynaecology, Aminu Kano Teaching Hospital/Bayero University Kano, Kano, \\ Nigeria \\ Email: zainabdatti@yahoo.com
}

Received 30 April 2015; accepted 25 May 2015; published 27 May 2015

Copyright (C) 2015 by authors and Scientific Research Publishing Inc.

This work is licensed under the Creative Commons Attribution International License (CC BY). http://creativecommons.org/licenses/by/4.0/

c) (i) Open Access

\section{Abstract}

Background: Hysterectomy, is a common operation worldwide. It is a major surgery, which leads to significant morbidity and mortality, hence, there must be a justifiable indication before the procedure is undertaken. Symptomatic uterine fibroid and utero-vaginal prolapse are common indications in this environment. Objectives: To determine the prevalence, indications and outcome of hysterectomy at Aminu Kano Teaching Hospital, Kano. Study Design: A retrospective study of all the hysterectomies that were done in Aminu Kano Teaching Hospital, Kano between 1st of Jan 2009 and 31st of Dec 2013. Result: During the period of study, there were 3843 major gynaecological operations. Out of which hysterectomy was 196, giving hysterectomy rate of $5.1 \%$ of all major gynaecological operations. Hysterectomy was highest among patient aged 40 - 49 years accounting for $54.6 \%$ of cases and the commonest indication was uterine fibroid, constituting $66.4 \%$ of all hysterectomies. Total abdominal hysterectomy was the most frequently preformed, accounting for $\mathbf{7 8 . 1 \%}$ while, vaginal hysterectomy accounts for $\mathbf{2 0 . 9 \%}$ of cases and subtotal hysterectomy was $1 \%$. Hysterectomy was mostly complicated with post-operative pyrexia constituting $24 \%$ of all the complications while ureteric injury was the least, constituting $1 \%$. There was no mortality recorded. Most of the patients who had hysterectomy were discharge in less than 10th post-operative day accounting for $91.3 \%$ of cases. However, $80.5 \%$ of patients who had vagina hysterectomy were discharge in less than 5 th post-operative day. Conclusion: The prevalence of hysterectomy was $\mathbf{5 . 1 \%}$. Uterine fibroid was the commonest indication while postoperative pyrexia was the commonest complication found.

\section{Keywords}

Prevalence, Indication, Hysterectomy, Outcome, AKTH

\footnotetext{
${ }^{*}$ Corresponding author.
} 


\section{Introduction}

Hysterectomy is a major gynaecological operation for the removal of uterus with or without the adnexal structures. It is a common procedure in the United Kingdom, and United State of America [1].

In the United Kingdom, 20\% of women undergo hysterectomy before the age of 60 years [2]. In the United State, about 600,000 hysterectomies are performed annually and about a third and a quarter of women will have hysterectomy during their life time and before menopause respectively [1] [3].

In developed countries, hysterectomy is accepted readily, the case is however very different in developing countries where there is strong aversion to hysterectomy for reason of fear of surgery, loss of feminity, fear of reincarnation without uterus, sexual rejection by spouses or because of their strong cultural beliefs or religious attachment to preservation of menstruation and childbearing [4].

Hysterectomy may be done through the vaginal or abdominal route. The abdominal hysterectomy may be total or subtotal. Total abdominal Hysterectomy involves removal of uterus and cervix through an abdominal incision but subtotal hysterectomy is the removal of uterus through abdominal incision while sparing the cervix [5]-[9]. Vaginal hysterectomy is the removal of the uterus and cervix through the vagina, while performing a vaginal hysterectomy with the aid of laparoscopy is called laparoscopically assisted vaginal hysterectomy (LAVH) [5]. Radical hysterectomy is extensive surgery that in addition to removal of uterus and cervix, might include removal of lymph nodes, loose areolar tissue near major blood vessels, upper vagina and omentum [5]-[9]. This is mainly done for malignant cases [5]-[9].

In the 1940, 95\% of hysterectomies done in the United State of America were subtotal, but with more training, improved skill and desire to prevent cervical cancer, the removal of cervix at hysterectomy became a routine [10]. The incidence of cancer of the residual stump following subtotal hysterectomy is $0.3 \%$ [5] [8] [9]. Also the absence of uterine body fail to contain the growth of cervical stump cancer within the uterus and favors a more rapid and direct spread to bladder and at times the rectum [10]-[12]. The retained stump also serves as a plunger to form the apex of vaginal intussusception resulting in vault prolapse. In all cases where there is retained cervix, follow up exfoliative cytology is recommended [13].

However, some still emphasize the advantage of subtotal hysterectomy which include less mortality, reduced vaginal shortening and vault prolapse and increased sexual satisfaction [13]. But the pre-operative cervical smear cytology must be normal and subsequent follow up cervical smear should be guaranteed before subtotal hysterectomy will be advocated. In this part of the world where there is no organized cervical screening programs, total hysterectomy should be the aim except when it is technically difficult.

The vaginal procedure has been shown to be associated with less post-operative pain, less operative blood loss, less risk of trauma to the adjoining viscus, early ambulation, less hospital stay, less cost, and earlier return to normal activities [13]-[15]. Also there is less post-operative morbidity [13]-[15].

LAVH started in 1988, when the uterus was removed through the vaginal Vault using a Laparoscope. This has resulted in many hysterectomies that would otherwise have been done abdominal being done vaginally. Its advantage over total abdominal hysterectomy include less operatives blood loss, less operative morbidity, shorter hospital stay and quicker return to normal activities [12]. LAVH have the same advantage as vaginal hysterectomy except there is longer operating time [13] [14]. However, the drawback in Nigeria include high cost of surgery, relative unavailability of equipment and very few gynecological surgeons have the skill, as well as greater incidence of pelvic adhesion and much bigger uterine fibroid. In view of the overwhelming argument in favor of vagina hysterectomy, the gynaecologist should consider it first, only resorting to abdominal approach when the former is contraindicated.

The commonest indication for hysterectomy in our environment remain uterine fibroid with or without menorrhagia which is similar to that in developed countries except that uterine fibroid is generally larger and patients usually present late [16]. Other indications include dysfunctional uterine bleeding, pelvic organ prolapse, adenomyosis, cervical polyp, premalignant lesion of uterus and cervix after completion of family size, endometrial cancer, cervical cancer and chronic pelvic pain [1].

Complication that may occur following hysterectomy include hemorrhage, infection and injury to adjoining structure such as ureters, bladder and bowel etc. [5] [7]-[9]. These complications could lead to severe morbidity and even mortality [5] [7]-[9].

Obstetrics hysterectomies done as emergency, mostly indicated by rupture of uterus and severe post-partum haemorrhage secondary to persistence uterine atony, are not part of this study. 
A lot of studies have been done on hysterectomy but there has been none in this center. Therefore the purpose of this study is to determine the indication and outcome. It is hoped that the findings of this study will in future improve the management of patient that will require hysterectomy in our center.

\section{Aims and Objectives}

- To determine the prevalence and indications of hysterectomy in AKTH, Kano.

- To determine the outcome of hysterectomy in AKTH, Kano.

\section{Materials and Method}

It was a retrospective study of the hysterectomies done at Aminu Kano Teaching Hospital, Kano. Nigeria between 1st Jan 2009 and 31st Dec 2013. The patient's identification data were retrieved from gynaecological ward discharge record book and theater operation register. Their case notes were retrieved from medical Record department and analyzed for socio demographic characteristic, indications for surgery, type of hysterectomy, duration of hospital stay, post-operative morbidity and mortality. A post-operative temperature of $38^{\circ} \mathrm{C}$ or more on two consecutive days after the 1st day post-operative day was considered as pyrexia, a local erythema or suppuration was considered as wound Infection and a packed cell volume less than $30 \%$ was considered as anaemia.

The data was analyzed by simple percentage.

\section{Result}

During the period of study, there were 3843 major gynaecological operations. Out of which hysterectomy was 196 , giving a hysterectomy rate of $5.1 \%$ of all major gynaecological operations.

One hundred and ninety six folders were retrieved and analyzed. The socio-demographic characteristics of the patients are shown in Table 1. The hysterectomy was highest among patients 40 - 49 years age group constituting 54.6\%. It was commoner among higher parity than nulliparous. The commonest indication for hysterectomy was symptomatic uterine fibroid accounting for $62.3 \%$ of cases as in Table 2 while the commonest type of hysterectomy was total abdominal hysterectomy constituting $78.2 \%$ of cases as in Table 3 .

Furthermore, during the years under review, hysterectomy was mostly complicated with post-operative pyrexia constituting $24 \%$ of all complication while ureteric injury was the least, constituting $1 \%$ as shown in Table 6. There was no mortality recorded during the years under review.

Most of the patients who had hysterectomy were discharge less than 10th post-operative day accounting for 91.3\%. However, $80.5 \%$ of patients who had vagina hysterectomy were discharge less than 5th post-operative day as shown in Table 5.

\section{Discussion}

The prevalence of hysterectomy in this study was $5.1 \%$, this is by far lower than $40 \%$ reported by Joseph in Accra [17] and 8.5\% in Ilorin [18]. This disparity may be due to the general aversion to hysterectomy in northern part of Nigeria where Kano is situated and possibly cost of surgery. Also most patient with cervical cancer also presents with advanced disease.

Hysterectomy is commonest among the age group 40 - 49 years which constituted $54.6 \%$ of the total hysterectomy performed during the years under review as in Table 1. This is similar to other studies [5] [18]-[21].

Hysterectomy was commonest among grandmultipara accounting for $61.2 \%$ and least among nullipara accounting for $5.1 \%$. The indication for hysterectomy among nullipara were atypical endometrial hyperplasia, uncontrollable haemorrhage during attempt at myomectomy and uterine malignancy.

The commonest indication for hysterectomy in this study was uterine fibroid, accounting for $66.4 \%$ of the overall indications for hysterectomy as in Table 2. Similar findings were found in other studies [17] [18].

Total abdominal hysterectomy is the most frequently performed accounting for $78.2 \%$. This also agree with findings of various studies. [18]-[21] This is because subtotal hysterectomy is not favored except at caesarean hysterectomy, for the fear of cancer of the cervical stump and vaginal hysterectomy are mainly done for utero vaginal prolapse in our center. The ratio of abdominal hysterectomy to vaginal hysterectomy is $4: 1$ as shown in Table 3 which is similar to other studies. [20] [22] However lower than Ibadan with ratio of 9:1. [23] Subtotal 
Table 1. Socio-demographic of study patients. (a) Age distribution of patients who had hysterectomy; (b) Parity of patients who had hysterectomy.

(a)

\begin{tabular}{ccc}
\hline Age & Number & $\%$ \\
\hline$<30$ & 0 & 0 \\
$30-39$ & 33 & 16.8 \\
$40-49$ & 107 & 54.6 \\
$50-59$ & 29 & 14.8 \\
$60-69$ & 18 & 9.2 \\
$\geq 70$ & 9 & 4.6 \\
Total & 196 & 100 \\
\hline
\end{tabular}

(b)

\begin{tabular}{ccc}
\hline Parity & Number & $\%$ \\
\hline 0 & 10 & 5.1 \\
$1-4$ & 66 & 33.7 \\
$\geq 5$ & 120 & 61.2 \\
Total & 196 & 100 \\
\hline
\end{tabular}

Table 2. Indications for hysterectomy.

\begin{tabular}{ccc}
\hline Indication & Number & $\%$ \\
\hline Symptomatic Uterine fibroid & 112 & 62.3 \\
Utero vaginal prolapse & 32 & 16.3 \\
CIN & 10 & 5.1 \\
Endometrial hyperplasia & 12 & 6.1 \\
Ovarian tumour & 8 & 4.1 \\
Uterine malignancy & 8 & 4.1 \\
Cervical malignancy & 4 & 2.0 \\
Total & 196 & 100 \\
\hline
\end{tabular}

Table 3. Type of hysterectomy.

\begin{tabular}{ccc}
\hline Type & Number & $\%$ \\
\hline TAH & 153 & 78.1 \\
VH & 41 & 20.9 \\
STAH & 2 & 1.0 \\
Total & 196 & 100 \\
\hline
\end{tabular}


hysterectomy was done for two patients (5.1\%) as the need for hysterectomy became necessary intra-operatively as a result of uncontrollable haemorrhage during attempt at myomectomy. This may be due to the fact that, it was the fastest and easiest at that moment.

Forty two hysterectomies accounting for $21.4 \%$ of cases were done by Senior Registrars under consultant supervision while $78.6 \%$ were performed by consultants.

The patients who had hysterectomy in the study were discharge from hospital less than 10th post-operative day accounting for $91.3 \%$ of cases The figure is lower than figure reported in United State, [1] but comparable with that reported by Olumuyiwa et al. [19] and Bukar et al. [20].

Variation in the causes of post-operative pyrexia may be responsible for this disparity. Kano like many other parts of Nigeria and Africa as a whole is a malaria endemic zone, so very frequently malaria complicates post-operatives period and could prolong post-operative hospital stay. Abdominal sutures are routinely removed by the 7th post-operative day for mid line sub-umbilical incision in our unit. This also could had resulted in an undue prolonged hospital day.

However $80.5 \%$ of patients who had vaginal hysterectomy were discharge less than 5th post-operative day as in Table 4, Table 5. Similar findings have been reported [20].

Post-operative pyrexia (24\%) and wound infection (11.2\%) were the commonest post-operative complication in this study as shown in Table 6, Table 7. This agrees with the findings of many other studies carried out in different centre [19]-[22]. Malaria and the surgical technique could have been responsible for the high postoperative pyrexia and wound infection respectively. There were two cases of ureteric injury which was managed successfully. This ureteric injury had also been documented in several studies [24]-[26]. There was no mortality associated with hysterectomy during the years under review.

Table 4. Cadre of surgeons that performed hysterectomy.

\begin{tabular}{ccc}
\hline Cadre & Number & $\%$ \\
\hline Senior Registrar & 42 & 21.4 \\
Consultant & 152 & 78.6 \\
Total & 196 & 100 \\
\hline
\end{tabular}

Table 5. Length of hospital stay of patients who had hysterectomy.

\begin{tabular}{ccc}
\hline No. of days & Number & $\%$ \\
\hline$<5$ & 33 & 16.8 \\
$5-9$ & 146 & 74.5 \\
$10-14$ & 13 & 6.7 \\
$>14$ & 4 & 2.0 \\
Total & 196 & 100 \\
\hline
\end{tabular}

Table 6. Comparison between length of hospital stay and type of hysterectomy.

\begin{tabular}{cccc}
\hline No. of days & VH & TAH & STAH \\
\hline 5 & 33 & 0 & 0 \\
$5-9$ & 8 & 132 & 2 \\
$10-14$ & 0 & 13 & 0 \\
$>14$ & 0 & 8 & 0 \\
Total & 41 & 153 & 2 \\
\hline
\end{tabular}


Table 7. Post-operative complication among patient who had hysterectomy.

\begin{tabular}{ccc}
\hline Complication & Number & $\%$ \\
\hline Pyrexia & 47 & 24.0 \\
Wound infection & 22 & 11.2 \\
Haemorrhage & 6 & 3.0 \\
Bladder injury & 5 & 2.6 \\
Bowel injury & 0 & 0 \\
Ureteric injury & 2 & 1.0 \\
Total & 82 & 41.8 \\
\hline
\end{tabular}

\section{Conclusions}

Hysterectomy is a commonly performed procedure worldwide. However, it is not a procedure that is readily accepted by our patients as a result of the premium attached to large family size and women who had hysterectomy are generally stigmatized. Also, the high prevalence of polygamy and high divorce rate are other factors that affect acceptance rate of hysterectomy. This explains the low hysterectomy rate of $5.1 \%$ obtained in our centre.

Post-operative morbidity as well as duration of hospital stay was less and convalescence was smoother among patients who had vaginal hysterectomy. Hence vaginal hysterectomy should be preferred over abdominal hysterectomy where it is not contraindicated due to its advantages

Furthermore, LAVH is a form of minimal access surgery that have the same advantages as vaginal hysterectomy and in addition faster recovery. However this procedure is not done in our centre because of nonavailability of the expertise and the necessary equipment. More so, most of the procedures were done for large uterine fibroid of more than 12 weeks size.

In view of the high rate of post-operative pyrexia and wound infection recorded in this study, prophylactic peri-operative antibiotics is recommended over post-operative antibiotic use which will in turn reduce length of hospital stay including overall cost.

It is hoped that other post-operative morbidities will be reduced by providing LAVH and this can be achieved through training of more gynaecologist in minimal in minimal access gynaecological surgeries as well as provision of necessary equipment. This is a treatment modality that yet unexplored in our centre.

Other studies in the future should focus on impact of educational status of patient on choice of hysterectomy, prevalence of vault prolapsed and impact of hysterectomy on sexual life.

\section{References}

[1] Patricia, G.M., Joellen, M.S., Edwin, S.I., Evan, R.M., Margaret, G., Nicolette, W.W. and Frances, W. (2009) A Prospective Study of Weight Gain after Premenopausal Hysterectomy. Journal of Women's Health, 18, 699-708. http://dx.doi.org/10.1089/jwh.2008.1019

[2] Patricia, G.M., Joellen, M.S., Edwin, S.I., Evan, R.M. and Frances, W. (2011) Reported Symptoms Before and One Year after Hysterectomy in African American and White Women. Journal of Women's Health, 20, 1035-1042. http://dx.doi.org/10.1089/jwh.2010.2543

[3] Okonofua, F.E. (2003) Infertility in Sub-Saharan Africa. In: Okonofua, F. and Odunsi, L., Eds., Contemporary Obstetrics and Gynaecology for Developing Countries, Women's Health and Action Research Centre, 128-156.

[4] Omigbodun, A.O. and Ayinde, O.A. (2003) Novel Approaches to the Treatment of Uterine Leiomyomata. Tropical Journal of Obstetrics and Gynaecology, 20, 1-3.

[5] Tindall, V.R. (1986) Tumor of the Cervix Uteri: In M Jeff Coates’s Principle of Gynaecology. 5th Edition, Butter Worth, London, 395-416.

[6] Ray, G. (2005) The Future of Hysterectomy. British Journal of Obstetrics and Gynaecology, 122, $133-139$.

[7] Onwuhafua, P.I., Ogunlayo, A., Adesuyin, G., Obineche, I. and Akuse, T.J. (2005) Audit of Hysterectomy in a Group 
of Private Hospitals in Kaduna City, Northern Nigeria. Tropical Journal of Obstetrics and Gynaecology, 1, 16-20.

[8] Onah, H.E. and Ugona, N.C. (2004) An Audit of Vaginal Hysterectomies in Enugu, Nigeria. Tropical Journal of Obstetrics and Gynaecology, 21, 58-60.

[9] Al Kadiri, H.M., Al-Turki, H.A. and Saleh, A.M. (2002) Short and Long Term Complication of Abdominal and Vaginal Hysterectomy from Benign Disease. Saudi Medical Journal, 23, 806-810.

[10] Jones, H.W. (2003) Hysterectomy in Telindes’ Operative Gynaecology. In: Rock, J.A. and Jones, H.W., Eds., 9th Edition, Lippincot Williams and Wilkins, 799-828.

[11] Reich, H., DeCaprio, J. and McGlynn, F. (1989) Laparoscopic Hysterectomy. Journal of Gynecologic Surgery, 5, 213216. http://dx.doi.org/10.1089/gyn.1989.5.213

[12] Chang, W.-C., Huang, S.-C., Sheu, B.-C., Chen, C.-L., Torng, P.-L., Hsu, W.-C. and Chang, D.-Y. (2005) Transvaginal Hysterectomy or Laparoscopically Assisted Vaginal Hysterectomy for Nonprolapsed Uteri. Obstetrics \& Gynecology, 106, 321-326. http://dx.doi.org/10.1097/01.AOG.0000171106.39216.17

[13] Shiota, M., Kotani, Y., Umemoto, M., Tobiume, T., Shimaoka, M. and Hoshiai, H. (2011) Total Abdominal Hysterectomy versus Laparoscopically-Assisted Vaginal Hysterectomy versus Total Vaginal Hysterectomy. Asian Journal of Endoscopic Surgery, 4, 161-165. http://dx.doi.org/10.1111/j.1758-5910.2011.00104.X

[14] Jahan, S., Das, T.R., Mahmud, N., Mondol, S.K., Habib, S.H., Saha, S., et al. (2011) A Comparative Study among Laparoscopically Assisted Vaginal Hysterectomy, Vaginal Hysterectomy and Abdominal Hysterectomy: Experience in a Tertiary Care Hospital in Bangladesh. Journal of Obstetrics \& Gynaecology, 31, 254-257. http://dx.doi.org/10.3109/01443615.2010.550346

[15] Ribeiro, S.C., Ribeiro, R.M., Santos, N.C. and Pinotti, J.A. (2003) A Randomized Study of Total Abdominal, Vaginal Laparoscopic Hysterectomy. International Journal of Gynecology \& Obstetrics, 83, 37-43. http://dx.doi.org/10.1016/S0020-7292(03)00271-6

[16] Okogbenin, S.A., Eigbefoh, J.I., Okonta, P.I. and Onuh, S.O. (2004) Abdominal Hysterectomy for Gynaecological Disease-Six Year Review in UBTH. Tropical Journal of Obstetrics and Gynaecology, 21, S29-S30.

[17] Joseph, D.S. and Richard, M.K.A. (2005) Hysterectomy for Uterine Fibroid in Nulliparae at Korlu BU Teaching Hospital Ghana. Tropical Journal of Obstetrics and Gynaecology, 8, 125-128.

[18] Oyewoye, O.A. (1998) Elective Hysterectomy at Ilorin, Nigeria-4 Years Review. Journal of Obstetrics \& Gynaecology, 18, 72-75.

[19] Olumuyiwa, A.R. and Michael, A.O. (2001) Abdominal Hysterectomy for Benign Gynaecological Conditions at Ibadan, Nigeria. Tropical Journal of Obstetrics and Gynaecology, 18, 19-23.

[20] Bukar, M., Audu, B. and Yahaya, U. (2010) Hysterectomy for Benign Gynaecological Conditions at Gombe, North Eastern Nigeria. Nigerian Medical Journal, 51, 35-38.

[21] Akagbosu, F.T. (1996) Audit of Abdominal Hysterectomies at University of Benin Teaching Hospital. Journal of Obstetrics \& Gynaecology, 16, 6-12. http://dx.doi.org/10.3109/01443619609030059

[22] Obiechina, N.J., Ugboaja, J.O., Onyegbule, O.A. and Eleje, G.U. (2010) Vaginal Hysterectomy in a Nigerian Tertiary Health Facility. Nigerian Journal of Medicine, 19, 324-325. http://dx.doi.org/10.4314/njm.v19i3.60228

[23] Ocheke, A.N., Ekwempu, C.C. and Musa, J. (2009) Underutilization of Vaginal Hysterectomy and Its Impact on Residency Training. West African Journal of Medicine, 28, 323-326.

[24] Arowojolu, A.O. (2003) Hysterectomy. In: Okonofua, F. and Odunsi, K., Eds., Contemporary Obstetrics and Gynaecology for Developing Countries, Women's Health and Action Research Centre, Benin City, 227-242.

[25] Sait, K., Alkhattabi, M., Boker, A. and Alhashemi, J. (2008) Hysterectomy for Benign Conditions in a University Hospital in Saudi Arabia. Annals of Saudi Medicine, 28, 282-286.

[26] Pokras, R. and Hufragel, V.G. (1987) Hysterectomy in the United States. Vital Health Statistics. Series 13, No. 92, Washington DC Government Printing Office, DHHS Publication No. (PHS) 88-1753. 